Case Report

\title{
Facial Swelling in the Presence of a COVID-19 Diagnosis: Case Report
}

\author{
Jenelle Fleagle * and Margarita Lorch *(1) \\ Nemours / Alfred I. duPont Hospital for Children, Wilmington, DE 19803, USA \\ * Correspondence: jenelle.fleagle@nemours.org (J.F.); mlorch@nemours.org (M.L.)
}

check for

updates

Citation: Fleagle, J.; Lorch, M. Facial Swelling in the Presence of a COVID-19 Diagnosis: Case Report. Oral 2021, 1, 102-107. https:// doi.org/10.3390/oral1020010

Academic Editor:

Giuseppina Campisi

Received: 22 March 2021

Accepted: 15 April 2021

Published: 22 April 2021

Publisher's Note: MDPI stays neutral with regard to jurisdictional claims in published maps and institutional affiliations.

Copyright: (C) 2021 by the authors. Licensee MDPI, Basel, Switzerland. This article is an open access article distributed under the terms and conditions of the Creative Commons Attribution (CC BY) license (https:// creativecommons.org/licenses/by/ $4.0 /)$.

\begin{abstract}
COVID-19 became a pandemic with a worldwide impact leading to stay-at-home orders, death, economic difficulties, and a significant influence on daily lives. Dental services became limited at this time, causing increased concerns for patients requiring urgent dental care. We report the case of a 5-year-old previously healthy male who presented to our hospital's emergency department (ED) with facial swelling secondary to infected maxillary left molars. Extractions were performed in the ED with moderate sedation. He was later found to be COVID-19 positive before admission for intravenous antibiotics. The use of universal precautions during the pandemic in treating patients with possible COVID-19 symptoms and in aerosol-generating procedures is recommended. Evaluating and providing treatment to our patients with urgent dental care should not be delayed to prevent further complications and decrease the burden placed on the ED, which may be limited in its ability to provide definitive care.
\end{abstract}

Keywords: pandemic; COVID-19; dental; emergency department

\section{Introduction}

The novel coronavirus disease (COVID-19) was first identified in Wuhan, China, in late 2019 [1]. It quickly became a pandemic with a worldwide impact leading to stay-athome orders, death, economic difficulties, and a significant influence on daily lives. In the U.S., more than eight million people have tested positive for COVID-19 [2], and an even greater number of people are secondarily affected by COVID-19 through the inability to receive routine services, such as dental treatment.

On 13 March 2020, the U.S. declared a national emergency due to the COVID-19 pandemic. This led to limitations of all nonemergency medical services, including dental offices. Emergency department (ED) trends at this time showed patient reservations with seeking medical care [3], which may affect health care for years to come. The American Dental Association Health Policy Institute completed a biweekly poll: The week of 23 March that showed $76 \%$ of dentists surveyed had closed their offices to all but emergency patients, and another 19\% indicated their offices had completely closed [4]. The limited dental services at this time caused increased concerns for patients requiring urgent dental care. The limited dental services caused patients to go to the ED for dental assessment and possible treatment. We discuss a patient who presented to the ED with facial swelling secondary to dental etiology and a positive COVID-19 test result. The aim of this report is to show how to care for a patient with a dental infection and the potential for a COVID-19 diagnosis during the pandemic.

\section{Case Report}

A 5-year-old previously healthy male presented to our institution on 6 May 2020. The presentation included pyrexia and significant upper left facial swelling. The patient was transferred from another hospital after receiving oral antibiotics with continued facial swelling (Figure 1). The patient's dental history included oral rehabilitation 6 months 
earlier with pulpal treatments and crowns. One week prior to this current admission, the patient was assessed at another ED and prescribed antibiotics. Of note, over the last 2 months, the patient's pediatric dental office was closed.

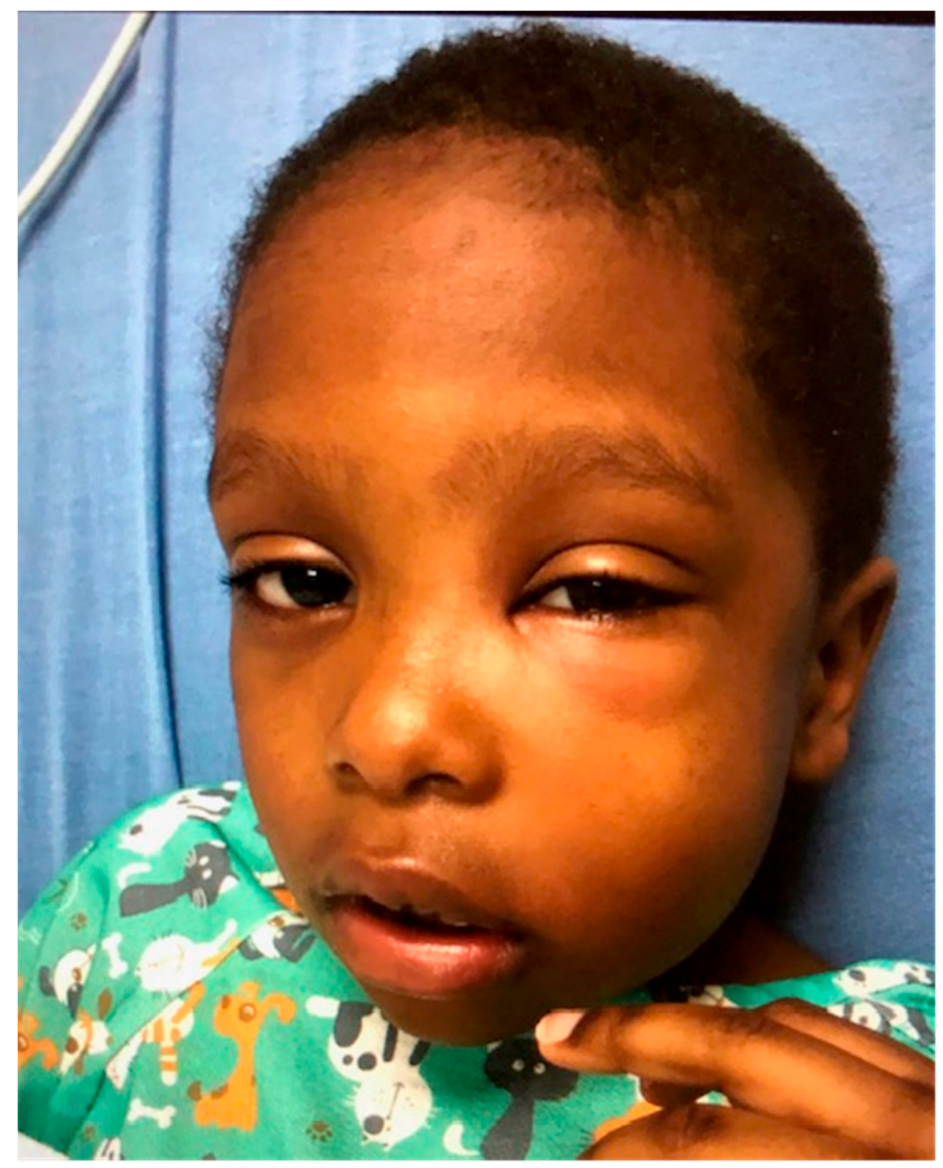

Figure 1. Facial swelling presentation to the emergency department.

Upon examination, the swelling appeared warm and fluctuant. The mandibular range of motion was $25 \mathrm{~mm}$, and enlarged left submandibular lymph nodes were present. The maxillary left molars caused significant discomfort with touch, greater than class II mobility, and white purulent discharge. The remaining teeth presented without mobility. Significant halitosis and no oral ulcers were present. Dental periapical films were taken showing the maxillary left molars with previous pulpotomies and crowns (Figure 2). Based upon these findings, the treatment recommendations included extractions under moderate sedation in the ED. 


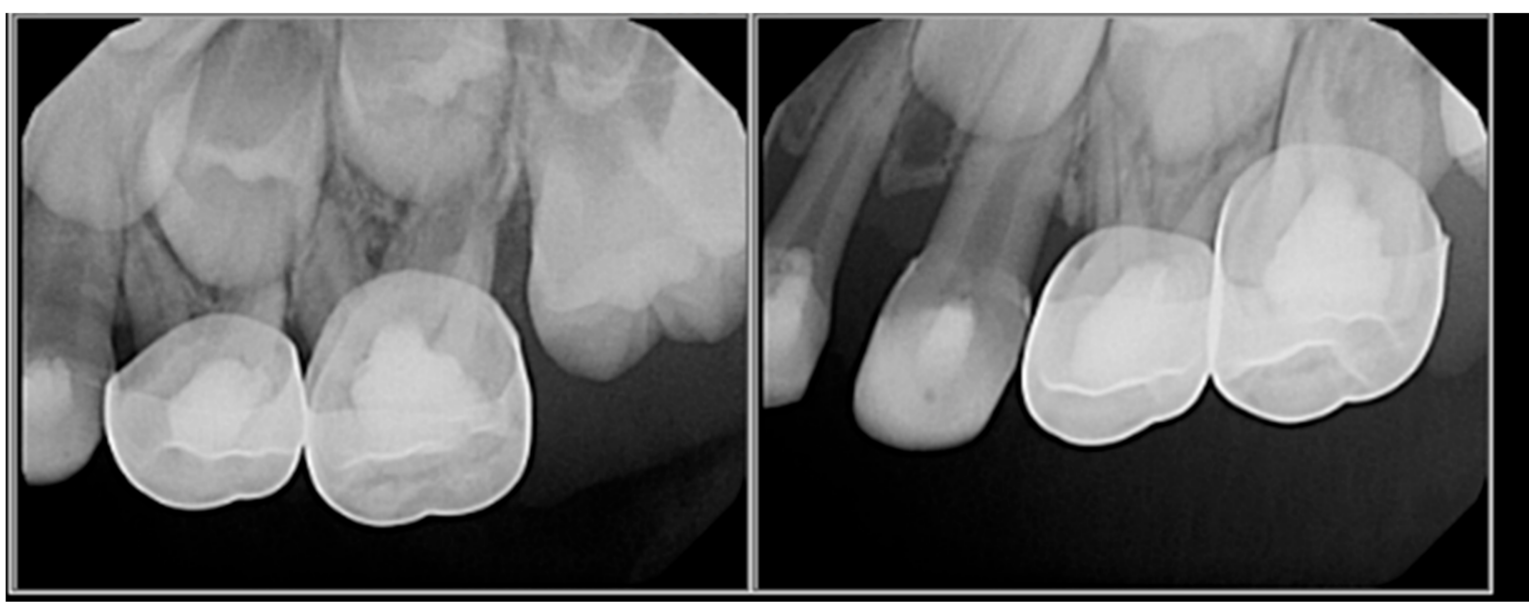

Figure 2. Dental radiographs taken in the emergency department at time of arrival.

Ketamine sedation was initiated by the ED team. Monitors were placed, time-out was completed, and intravenous (IV) weight-based ketamine was provided. The initial dose of ketamine was $1 \mathrm{mg} / \mathrm{kg}$ with two additional increments of $0.5 \mathrm{mg} / \mathrm{kg}$ given over approximately $15 \mathrm{~min}$ for a total of $40 \mathrm{mg}$. In addition, $36 \mathrm{mg}$ of 2\% lidocaine 1:100,000 local anesthesia was given. Extractions of the maxillary molars and incision and drainage were completed. Thick white purulent discharge was expressed and continued over many minutes. Throughout the sedation, the patient remained stable with the following vital signs: blood pressure, $105 / 66$; pulse, 94 ; temperature, $36.9{ }^{\circ} \mathrm{C}$; respiratory rate, 24 . Due to concerns for further space involvement, a computed tomography (CT) scan with contrast was completed (Figure 3), which showed no further involvement.

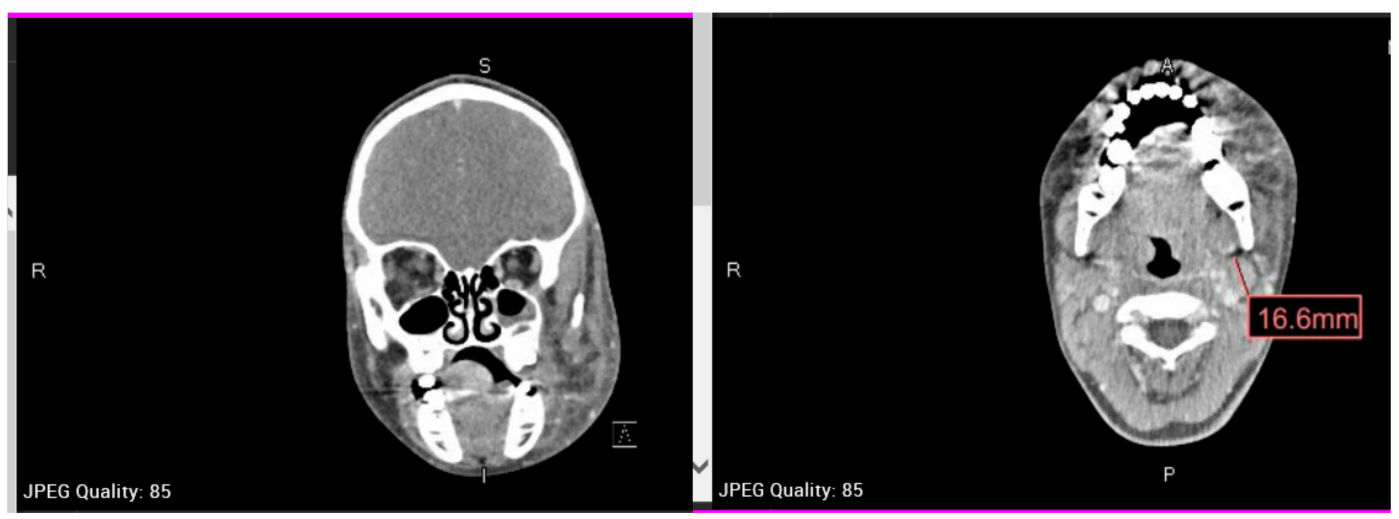

Figure 3. CT scan with contrast. Extraction sites in the left maxilla. No evidence of expansive periapical lucencies. There is a small focus of fluid collection with gas within the left buccal soft tissues adjacent to the extraction site consistent with postoperative nature.

In preparation for admission per our hospital's protocol, a COVID-19 test was completed, which was found to be positive. The patient was admitted to our COVID floor, where he was observed and given IV ampicillin and sulbactam for the dental abscess. The swelling significantly reduced over the next $24 \mathrm{~h}$ (Figure 4 ), and he was discharged home on amoxicillin and clavulanic acid. The patient remained with mild COVID-19 symptoms and recovered from COVID-19 uneventfully. Complete facial swelling resolution occurred on day seven. 

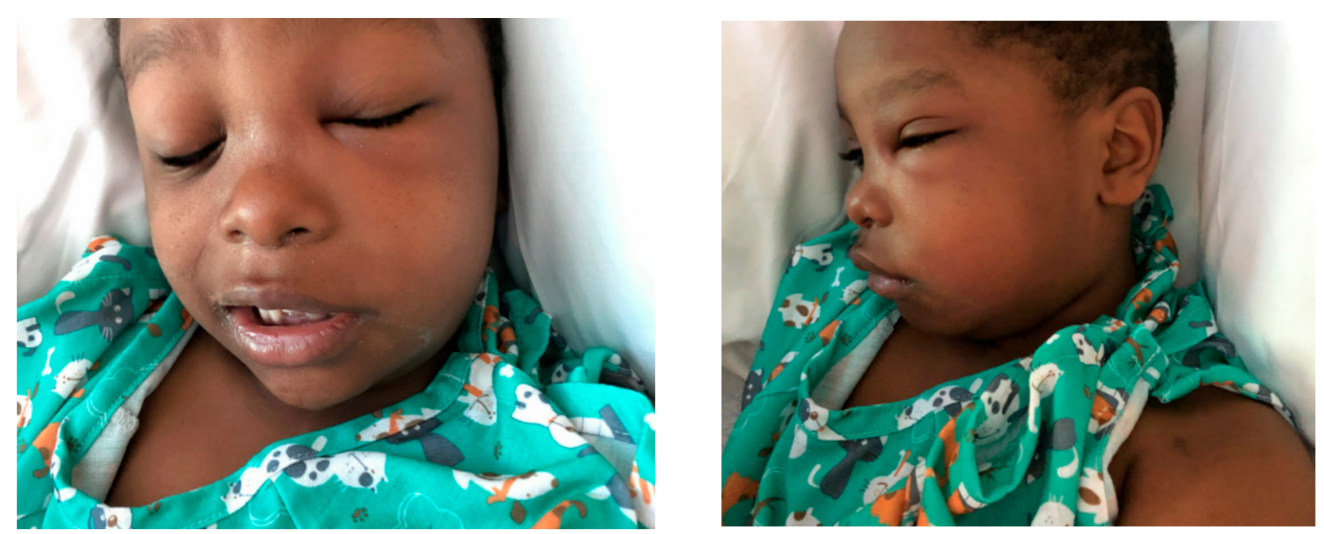

Figure 4. Postoperatively 24 h swelling.

\section{Discussion}

COVID-19 infections are generally mild in children compared to adults. The majority of patients with COVID-19 do not require hospitalization [5]. As of 22 October 2020, in the U.S., COVID-19 cases in the pediatric population represented $11.0 \%$ of all cases, with a rate of 1053 cases per 100,000 children in the population [6]. Recently in children, the use of serial $\mathrm{C}$-reactive protein (CRP) was found to be one of a few useful tests in monitoring the severity of disease, unlike in adults, where leukocyte indices have been shown to be more diagnostic in severity [7]. C-reactive protein is an inflammatory marker and may increase with the severity of COVID-19 [7]. We did not perform a blood test for CRP in our patient because of the relatively normal additional laboratory results, the significant improvement from treatment, and an expected high value due to the inflammatory response from the dental infection and rendered treatment.

Coinfections of respiratory disease with COVID-19 is another consideration that appears to impact patient outcomes. It is seen less than with previous influenza pandemics [5]; however, when also present, there is an increase in COVID-19 disease symptoms, difficulty with diagnosis and treatment, and mortality [8]. This may occur because of the susceptibility of a patient's immune function [8,9]. It is unknown if having a COVID-19 infection increases the severity of infections outside the respiratory system, such as in a dental infection, leading to further inflammation and severity of the bacterial infection.

Many studies have highlighted oral ulcerations as a sign of COVID-19 or manifestation of the deterioration of systemic health $[10,11]$. The oral manifestations that may appear concomitant with loss of taste and smell have been associated with dysgeusia, petechiae, candidiasis, traumatic ulcers, HSV-1 infection, geographical tongue, or thrush-like ulcers $[10,11]$. The angiotensin-converting enzyme 2 (ACE2) receptor, which has elevated expression in children [12], is detected in several cell membranes, including the epithelial cells of the tongue, salivary glands, and upper respiratory tracts. COVID-19 appears to target ACE2 receptors to enter the cells, thus leading to dysfunction and disruption of these membranes, such as the oral keratinocytes and epithelial lining, leading to ulcerations and dysgeusia $[10,11]$. Our patient was not known to develop further oral symptoms. He remained in isolation until his uneventful recovery.

The novel COVID-19 virus is thought to spread by close contact with people through respiratory droplets produced by talking, coughing, and sneezing [13]. COVID-19 has been shown to persist in aerosols for hours and may spread by asymptomatic people [13]. An aerosol procedure is defined as a procedure more likely to generate higher concentrations of infectious respiratory aerosols, which in dentistry involves rotary and surgical instruments such as handpieces, ultrasonic scalers, and triplex syringes [13,14]. Aerosol-generating procedures are commonplace with many dental procedures. In addition, nitrous oxide sedation, high-flow oxygen delivery, and patients with a tracheostomy may also generate aerosols [14]. It is strongly recommended to use universal procedures on all dental patients without a recent negative COVID-19 test [13]. 
A patient without a confirmed negative COVID-19 test at our hospital receiving an aerosol-generating procedure requires all providers to wear full personal protective equipment (PPE) as a precaution for asymptomatic carriage. The patient arrived with pyrexia, which was likely associated with his facial swelling secondary to a dental infection; however, all team members treating this patient wore full PPE, including eyewear and an N95 respirator. The $\mathrm{N} 95$ or other respirators are used because they offer an equivalent or higher level of protection during aerosol-generating procedures [13]. This highlights the continued use of universal dental precautions or the assumption that all patients are infected in order to prevent the transmission to our teams and spread to our communities $[13,14]$. The PPE is not without economic impact on hospitals, dental practitioners, limited PPE supply concerns, and environmental considerations $[15,16]$.

During the pandemic, it was difficult for many dental offices to navigate the everchanging requirements to serve their patients with urgent needs leading many to temporarily close. Aerosol-generating procedures are commonplace in dental offices, which may be more likely to spread COVID-19. Nitrous oxide sedation is another concern due to high-flow oxygen delivery in generating aerosols [14]. In many U.S. states, dental services were closed for elective dental treatment for approximately 3 months depending upon each state mandate [14]. In our case, the patient's mother made several attempts for dental assessment prior to the ED visits. Unfortunately, many patients during this time had difficulty receiving dental treatment and even more are suspected of avoiding earlier intervention due to fear [3,17]. The CDC now recommends dental services are essential to provide care in a way that minimizes harm to patients without delaying care, as happened in our case, as well as preventing potential exposure to COVID-19 [13].

Facial swelling with suspected COVID-19 may decrease early intervention and increase complications $[18,19]$. Often times facial swelling is of odontogenic origin; however, additional sources need to be ruled out [18]. Melkersson-Rosenthal Syndrome, a rare condition characterized by orofacial edema, facial paralysis, and a fissured tongue, was most recently described as being induced by COVID-19 [19]. The viral cells likely stimulated mast cells, which are present in the lungs, inducing an inflammatory response that results in cytokine production and the manifestation of respiratory infection and swelling. Although unreported, we can speculate that, like other viruses, facial swelling may be an uncommon association. Therefore, it is important to provide timely diagnosis and, when indicated, intervention with suspected or confirmed COVID-19 patients, especially in swelling, which continues to expand in size [18].

\section{Conclusions}

Patients should be screened for COVID-19 symptoms prior to dental treatment. In the event the urgency for dental treatment arises with a COVID-19 coinfection, PPE precautions, including eyewear and an N95 respirator, are indicated. It may be beneficial to provide antimicrobial mouth rinse to reduce oral cavity microbes, limit aerosol-generating procedures, and reduce procedures that may stimulate coughing [1]. Evaluation to confirm diagnosis and provision of treatment should not be delayed in order to prevent further complications.

Author Contributions: J.F. conceptualization, methodology, investigation, writing-original draft preparation, writing - review and editing, visualization. M.L. methodology, investigation, writingreview and editing, supervision. All authors have read and agreed to the published version of the manuscript.

Funding: The research received no funding.

Institutional Review Board Statement: The case report is an educational activity that does not meet IRB requirements for systematic investigation, research development, testing, and evaluation. This paper is developed to contribute to generalizable knowledge.

Informed Consent Statement: Written informed consent has been obtained from the patient's guardian to publish this paper. 
Data Availability Statement: Data sharing is not applicable to this article as no new data was created in this study.

Acknowledgments: Special thanks to the patient and his family.

Conflicts of Interest: The authors declare no conflict of interest.

\section{References}

1. Fini, M.B. What dentists need to know about COVID-19. Oral Oncol. 2020, 105, 104741. [CrossRef] [PubMed]

2. CDC. COVID Data Tracker. Updated 2020 October 26. Available online: https://covid.cdc.gov/covid-data-tracker/\#cases_ totalcases (accessed on 26 October 2020).

3. Hartnett, K.P.; Kite-Powell, A.; Devies, J.; Coletta, M.A.; Boehmer, T.K.; Adjemian, J.; Gundlapalli, A.V.; National Syndromic Surveillance Program Community of Practice. Impact of the COVID-19 Pandemic on Emergency Department Visits-United States, January 1, 2019-May 30, 2020. MMWR Morb. Mortal. Wkly. Rep. 2020, 69, 699-704. [CrossRef] [PubMed]

4. Carey, M.; American Dental Association (ADA). HPI Poll Examines Impact of COVID-19 on Dental Practices. ADA News. 1 April 2020. Available online: https://www.ada.org/en/publications/ada-news/2020-archive/april/hpi-poll-examines-impact-ofcovid-19-on-dental-practices (accessed on 5 August 2020).

5. Lansbury, L.; Lim, B.; Baskaran, V.; Lim, W.S. Co-infections in people with COVID-19: A systematic review and meta-analysis. J. Infect. 2020, 81, 266-275. [CrossRef] [PubMed]

6. American Academy of Pediatrics. Children and COVID-19: State-Level Data Report. Critical Updates on COVID-19. Updated 22 October 2020. Available online: https:/ / services.aap.org/en/pages/2019-novel-coronavirus-covid-19-infections/ (accessed on 26 October 2020).

7. Henry, B.M.; Benoit, S.W.; de Oliveira, M.H.S.; Hsieh, W.C.; Benoit, J.; Ballout, R.A.; Plebani, M.; Lippi, G. Laboratory abnormalities in children with mild and severe coronavirus disease 2019 (COVID-19): A pooled analysis and review. Clin. Biochem. 2020, 81, 1-8. [CrossRef] [PubMed]

8. Chen, X.; Liao, B.; Cheng, L.; Peng, X.; Xu, X.; Li, Y.; Hu, T.; Li, J.; Zhou, X.; Ren, B. The microbial coinfection in COVID-19. Appl. Microbiol. Biotechnol. 2020, 104, 1-9. [CrossRef] [PubMed]

9. Netea, M.G.; Giamarellos-Bourboulis, E.J.; Domínguez-Andrés, J.; Curtis, N.; Van Crevel, R.; Van De Veerdonk, F.L.; Bonten, M. Trained Immunity: A Tool for Reducing Susceptibility to and the Severity of SARS-CoV-2 Infection. Cell 2020, 181, 969-977. [CrossRef] [PubMed]

10. Brandão, T.B.; Gueiros, L.A.; Melo, T.S.; Prado-Ribeiro, A.C.; Nesrallah, A.C.F.A.; Prado, G.V.B.; Santos-Silva, A.R.; Migliorati, C.A. Oral lesions in patients with SARS-CoV-2 infection: Could the oral cavity be a target organ? Oral Surg. Oral Med. Oral Pathol. Oral Radiol. 2021, 131, e45-e51. [CrossRef] [PubMed]

11. Dos Santos, J.A.; Normando, A.G.C.; Da Silva, R.L.C.; De Paula, R.M.; Cembranel, A.C.; Santos-Silva, A.R.; Guerra, E.N.S. Oral mucosal lesions in a COVID-19 patient: New signs or secondary manifestations? Int. J. Infect. Dis. 2020, 97, 326-328. [CrossRef] [PubMed]

12. Behl, T.; Kaur, I.; Bungau, S.; Kumar, A.; Uddin, M.S.; Kumar, C.; Pal, G.; Shrivastava, K.; Zengin, G.; Arora, S. The dual impact of ACE2 in COVID-19 and ironical actions in geriatrics and pediatrics with possible therapeutic solutions. Life Sci. 2020, 257, 118075. [CrossRef] [PubMed]

13. American Dental Association (ADA). COVID-19 State Mandates \& Recommendations. Updated 8 August 2020. Available online: https:/ / success.ada.org/en/practice-management/patients/covid-19-state-mandates-and-recommendations (accessed on 26 October 2020).

14. Minnesota Department of Health. COVID-19 Aerosol-Generating Procedures and Patients with Suspected or Confirmed COVID19. Updated 22 July 2020. Available online: https:/ / www.health.state.mn.us/diseases/coronavirus/hcp/aerosol.pdf (accessed on 27 October 2020).

15. Livingston, E.H.; Desai, A.; Berkwits, M. Sourcing Personal Protective Equipment during the COVID-19 Pandemic. JAMA 2020, 323, 1912-1914. [CrossRef] [PubMed]

16. Chamorro-Petronacci, C.; Carreras-Presas, C.M.; Sanz-Marchena, A.; A Rodríguez-Fernández, M.; Suárez-Quintanilla, J.M.; Rivas-Mundiña, B.; Suárez-Quintanilla, J.; Pérez-Sayáns, M. Assessment of the Economic and Health-Care Impact of COVID-19 (SARS-CoV-2) on Public and Private Dental Surgeries in Spain: A Pilot Study. Int. J. Environ. Res. Public Health 2020, $17,5139$. [CrossRef] [PubMed]

17. Guo, H.; Zhou, Y.; Liu, X.; Tan, J. The impact of the COVID-19 epidemic on the utilization of emergency dental services. J. Dent. Sci. 2020, 15, 564-567. [CrossRef] [PubMed]

18. Ajeigbe, T.; Ria, B.; Wates, E.; Mattine, S. Severe parapharyngeal abscess that developed significant complications: Management during the COVID-19 pandemic. BMJ Case Rep. 2020, 13, e236449. [CrossRef] [PubMed]

19. Taşlıdere, B.; Mehmetaj, L.; Özcan, A.B.; Gülen, B.; Taşlıdere, N. Melkersson-Rosenthal Syndrome Induced by COVID-19. Am. J. Emerg. Med. 2021, 41, 262.e5-262.e7. [CrossRef] [PubMed] 